\title{
Feasibility of a self-administered survey to identify primary care patients at risk of medication-related problems
}

This article was published in the following Dove Press journal:

Journal of Multidisciplinary Healthcare

22 February 2014

Number of times this article has been viewed

\author{
Mark J Makowsky' \\ Andrew J Cave ${ }^{2}$ \\ Scot H Simpson' \\ 'Faculty of Pharmacy and \\ Pharmaceutical Sciences, ${ }^{2}$ Department \\ of Family Medicine, Faculty of \\ Medicine and Dentistry, University \\ of Alberta, Edmonton, AB, Canada
}

Background and objectives: Pharmacists working in primary care clinics are well positioned to help optimize medication management of community-dwelling patients who are at high risk of experiencing medication-related problems. However, it is often difficult to identify these patients. Our objective was to test the feasibility of a self-administered patient survey, to facilitate identification of patients at high risk of medication-related problems in a family medicine clinic.

Methods: We conducted a cross-sectional, paper-based survey at the University of Alberta Hospital Family Medicine Clinic in Edmonton, Alberta, which serves approximately 7,000 patients, with 25,000 consultations per year. Adult patients attending the clinic were invited to complete a ten-item questionnaire, adapted from previously validated surveys, while waiting to be seen by the physician. Outcomes of interest included: time to complete the questionnaire, staff feedback regarding impact on workflow, and the proportion of patients who reported three or more risk factors for medication-related problems.

Results: The questionnaire took less than 5 minutes to complete, according to the patient's report on the last page of the questionnaire. The median age (and interquartile range) of respondents was 57 (45-69) years; 59\% were women; 47\% reported being in very good or excellent health; 43 respondents of 100 had three or more risk factors, and met the definition for being at high risk of a medication-related problem.

Conclusions: Distribution of a self-administered questionnaire did not disrupt patients, or the clinic workflow, and identified an important proportion of patients at high risk of medicationrelated problems.

Keywords: screening tool, pharmacists, primary care, medication related problems

\section{Background}

Pharmacists embedded in primary care medical practices, such as those modeled on the patient-centered medical home, are playing increasing roles in interdisciplinary primary healthcare teams. ${ }^{1-3}$ However, with limited pharmacist resources and high patient to pharmacist ratios, it is important to identify which patients would benefit most from consultation with a primary care pharmacist. We have previously completed a similar assessment of patient requirements for dietician services in primary care. ${ }^{4}$ While commonly used approaches to identify patients for pharmacist care include physician referrals, drug- or disease-specific programs (eg, chronic disease management), and patients recently discharged from hospital, an alternative strategy is to focus on patients at increased risk of medication-related problems (MRPs). ${ }^{2,5-7}$ MRPs are events or circumstances involving drug therapy that actually, or potentially, interfere
Correspondence: Andrew J Cave Department of Family Medicine, Faculty of Medicine and Dentistry, University of Alberta, 901 College Plaza, Edmonton, AB T6G 2R3, Canada

$\mathrm{Tel}+\mathrm{I} 7804928102$

Fax +I 7804922593

Email andrew.cave@ualberta.ca 
with an optimum outcome for the patient. ${ }^{8,9}$ Several studies have identified factors associated with an increased risk of MRPs, ${ }^{10-14}$ and short, self-administered surveys have been developed to help identify patients at risk of MRPs. ${ }^{12,15}$

Our objective was to determine the feasibility of using a locally adapted, self-administered, paper-based, patient survey, to identify patients at risk of MRPs, in a convenience sample of patients at a single academic family medicine clinic.

\section{Methods}

\section{Design and setting}

We conducted a cross-sectional pilot study based on a convenience sample of 100 completed surveys at the University of Alberta Hospital Family Medicine Clinic in Edmonton. At the time of the survey, seven family physicians, two family medicine resident doctors, two full time clinic nurses (one dedicated to chronic disease management), and two academic clinical pharmacists (each working $\sim 0.2$ full-time equivalent) provided service to approximately 7,000 patients.

All patients registered to be seen by one of the clinic physicians were eligible to participate in this survey, unless they were less than 18 years old, could not read English, or were not responsible for self-management of their medications. After registration at the reception desk, a medical office assistant asked eligible patients if they would be willing to participate. Those who expressed interest were given an information letter and a copy of the survey as they were placed in an examination room, and asked to complete the survey while waiting to be seen by their physician. The University of Alberta Health Research Ethics Board (REB) approved the study protocol. Consent to participate was assumed if a patient returned the completed questionnaire. No record was kept of the number of patients approached.

\section{Survey}

We used the previously validated, ten-item MRP questionnaire, developed by Barenholtz Levy, and the modified fiveitem questionnaire, developed by Langford et al, to create an adapted ten-item questionnaire (Figure 1). ${ }^{12,15}$ To adapt the questionnaire for the primary care ambulatory population, several changes were made. The two most significant changes made were: 1) the focus of Question 3 (present in both surveys) was changed from high risk medications to a chronic diseases focus, and 2) Question 9, "Does someone else bring any of your medications to your home for you?" was replaced (as all patients attending the family medicine clinic were ambulatory) with "Do you sometimes worry about the long-term effects of your medications?"

\section{Data analysis}

To determine feasibility, we recorded patient-reported time to complete the questionnaire, and we solicited opinions from the medical office assistants and physicians about the impact of the questionnaire on clinic flow. To estimate the number of patients at high risk for an MRP, we calculated a summary risk score. This was done by adding the number of "yes" responses, after collapsing Question 3 into a single "yes" or "no" response. The response to Question 6 was reversed, to correct for the negative stem. As done by others in the literature, we defined patients who answered "yes" to three or more questions as being at high risk for a MRP. ${ }^{11,15,16}$ To allow further comparisons, we did a sensitivity analysis, in which we examined the number of patients who were at risk, while restricting analysis to the five questions developed by Langford et al. ${ }^{15}$

\section{Results}

The questionnaire was distributed during May-December, 2009. Demographic characteristics, summary risk scores, and time to complete the questionnaire are presented in Table 1. From patient reports in answer to the questionnaire, the median time to complete the questionnaire was 2 minutes (interquartile range: 1.5-3 minutes). There were no comments from the medical office assistants, or physicians approached during regular staff meetings, to suggest that the questionnaire was intrusive on the clinic's workflow. The questionnaire was not distributed by medical office assistants to consecutive patients, because research was not considered to be a priority in their responsibilities, and clinical tasks sometimes intervened. This reflects the real-life situation in practice. Forty-three respondents had three or more risk factors identified by the full ten-point questionnaire, and 26 respondents met this criterion in the sensitivity analysis.

In view of the limited data, and bearing in mind that this was a pilot study, no further mining of the data was undertaken.

\section{Discussion}

The findings of this pilot study suggest that distribution of a MRP questionnaire at the point of care is feasible in a busy family medicine clinic, and that there was a strong signal for potential MRPs in the sample studied. However, there may have been a selection bias introduced by the office 


\section{University of Alberta Hospital Family Medicine Clinic Medication risk assessment questionnaire}

Please complete all questions below to the best of your ability

1. Do you take $\mathbf{5}$ or more different medications?

(including prescription, non-prescription, and herbal therapies)

2. Do you take $\mathbf{1 2}$ or more pills each day?

(including prescription, non-prescription, herbal therapies)

3. Do you take any medications for ...

$\begin{array}{llr}\text { Nerves, stress, anxiety, or depression } & \square \text { No } & \square \text { Yes } \\ \text { Blood pressure or heart disease } & \square \text { No } & \square \text { Yes } \\ \text { Arthritis or pain } & \square \text { No } & \square \text { Yes } \\ \text { Diabetes } & \square \text { No } & \square \text { Yes } \\ \text { Lung disease } & \square \text { No } & \square \text { Yes }\end{array}$

4. Does more than $\mathbf{1}$ physician prescribe medications for you on a regular basis?

5. Are you taking medications for $\mathbf{3}$ or more medical problems?

$\square$ No

6. Do you get all your prescriptions filled at the same pharmacy?

7. Have your medications, or the instructions on how to take them, changed $\mathbf{4}$ or more times in the past year?

8. Do you have difficulties taking your medications as prescribed?

9. Do you sometimes worry about the long-term effects of your medications?

10. Do you have any unanswered questions about your medications?

Figure I The questionnaire.

assistants, in terms of who they approached to participate, especially when they were busy. We have identified issues relating to the efficiency of this approach (consecutive patients were not all approached), and we suggest that asynchronous methods to systematically screen larger numbers of patients, such as the use of electronic medical record data, should also be explored to supplement the direct approach. This anonymous pilot study, as approved by the REB, did not permit the pharmacists to act upon the MRPs identified, whereas a chart survey would allow this.

This study adds to existing literature that demonstrates in practice the clinical utility of a MRP screening tool, and demonstrates its potential to generate pharmacist referrals. While our overall estimate of patients at high risk for an MRP was double that obtained by Langford et $\mathrm{a}^{15}$ ( $43 \%$ versus $18 \%$, respectively), our sensitivity analysis, using only Langford's questions, demonstrated more similar proportions (26\% versus $18 \%)$. The difference is likely related to the change in focus of one question, from high risk medications to the presence of common chronic diseases. In view of the differences between the two studies, no statistical comparison was made. Unfortunately, comparisons with the sample studied by Barenholtz Levy are not possible, as they did not report summary risk scores, nor use a cut-off to define patients as being at high risk. ${ }^{12}$

Perhaps one of our study's biggest strengths was its use of medical office assistant staff to screen patients, rather than using research personnel or clinic pharmacists. From a practical standpoint, part-time clinic pharmacists are not available to screen all patients attending clinics. Despite this strength, there are several limitations. Since our study was an uncontrolled, single site, cross sectional survey based on a convenience sample, the time taken to achieve $100 \mathrm{com}$ pleted surveys, as well as our estimates of the proportions of patients at high risk of MRPs, may be unreliable. Framing the survey as "research" to the office assistants (rather than quality improvement) may have contributed to the prolonged recruitment period; this was also contributed to by 
Table I Demographic characteristics and medication risk assessment questionnaire responses

\begin{tabular}{|c|c|}
\hline & $\begin{array}{l}\text { Respondents } \\
(\mathrm{n}=100)\end{array}$ \\
\hline \multicolumn{2}{|l|}{ Demographics } \\
\hline Age (median, interquartile range) & $56.5(45-68.5)$ \\
\hline Male & 41 \\
\hline Rating of general health (median, interquartile range) & $3(3-4)$ \\
\hline Poor & 4 \\
\hline Fair & 13 \\
\hline Good & 38 \\
\hline Very good & 36 \\
\hline Excellent & 9 \\
\hline $\begin{array}{l}\text { Time to complete the survey (minutes) } \\
\text { (median, interquartile range) }\end{array}$ & $2(1.5-3)$ \\
\hline \multicolumn{2}{|l|}{ Proportion of respondents with individual risk factors } \\
\hline$\geq 5$ medications taken daily & 37 \\
\hline$\geq 12$ doses taken daily & 18 \\
\hline Any target conditions & 70 \\
\hline$\geq I$ physician prescribing medications & 23 \\
\hline$\geq 3$ medical conditions & 36 \\
\hline Medications not filled at same pharmacy & 10 \\
\hline$\geq 4$ changes to medications in past year & 8 \\
\hline Difficulties taking medications & 6 \\
\hline Worry about medications & 40 \\
\hline Unanswered questions about medications & 7 \\
\hline \multicolumn{2}{|l|}{ Summary risk score } \\
\hline 0 & 13 \\
\hline I & 23 \\
\hline 2 & 21 \\
\hline 3 & 13 \\
\hline 4 & 13 \\
\hline 5 & 8 \\
\hline 6 & 4 \\
\hline 7 & 5 \\
\hline $8+$ & 0 \\
\hline $\begin{array}{l}\text { At risk of medication-related problem? ( } 3 \text { or more } \\
\text { risk factors) }\end{array}$ & 43 \\
\hline
\end{tabular}

the deliberate "arms' length" policy of the investigators, to test the feasibility of the intervention in the practice context. It would seem that such a screening approach would need more direct supervision. Volunteer bias or preselection by medical office assistants could have led to overestimation of those at high risk. Finally, as demonstrated by our sensitivity analysis, the reliability of this estimate is influenced by the number of questions included in the survey, and the arbitrary nature of the cut-off points to define high risk. Future study is required to compare different methods of patient identification for primary care pharmacists, determine what threshold accurately defines high risk of an MRP, and, ultimately, the effect of pharmacist intervention on risk of MRPs.

In conclusion, our results suggest that screening patients at the point of care, using a self-administered MRP questionnaire, was feasible, and that a large proportion of those who complete the questionnaire will have multiple risk factors for MRPs. This is similar to the opportunity found in our dietician study. ${ }^{4}$ However, other strategies, including electronic medical record screening or focusing on patients attending the chronic disease management nurse, may represent complementary methods to increase screening efficiency, and allow for more systematic screening of clinic patients for risk of MRPs. Our findings support the integration of a pharmacist into family medicine practices, as a member of the patient-centered medical home. Future work will include further content and construct validation of the revised tool and its predictive ability for measures of health care utilization. Additionally, we plan to compare the predictive accuracy and feasibility of an automated electronic medical record medication list screening approach for identifying patients at high risk of MRPs.

\section{Disclosure}

The authors report no conflicts of interest in this work.

\section{References}

1. Smith M, Bates DW, Bodenheimer T, Cleary PD. Why pharmacists belong in the medical home. Health Aff (Millwood). 2010;29: 906-913.

2. Dolovich L, Pottie K, Kaczorowski J, et al. Integrating family medicine and pharmacy to advance primary care therapeutics. Clin Pharmacol Ther. 2008;83:913-917.

3. Simpson SH, Majumdar SR, Tsuyuki RT, Lewanczuk RZ, Spooner R, Johnson JA. Effect of adding pharmacists to primary care teams on blood pressure control in patients with type 2 diabetes: A randomized controlled trial. Diabetes Care. 2011;34:20-26.

4. Harland-Gregoire MJ, Chow S, Spooner GR, Cave AJ, Klemka PJ. A screening instrument to identify adults with nutritional risk in a family medicine practice. Can J Diet Prac Res. 1999;60:205-211.

5. Carter BL, Bosworth HB, Green BB. The hypertension team: the role of the pharmacist, nurse, and teamwork in hypertension therapy. J Clin Hypertens (Greenwich). 2012;14:51-65.

6. Bailey AL, Moe G, Moe J, Oland R. Implementation and evaluation of a community-based medication reconciliation (CMR) system at the hospital-community interface of care. Healthc $Q$. 2009;13 Spec No: 91-97.

7. Wong C, Cave AJ, Jarman R. Pharmaceutical care in a family medicine centre. Can Pharm J. 1997;130:35-43.

8. MacKinnon N. Glossary: Adverse Drug Related Consequences. In: MacKinnon, NJ. eds. Safe and Effective. Ottawa, ON. Canadian Pharmacists Association. 2007:471-474.

9. Hepler CD, Strand LM. Opportunities and responsibilities in pharmaceutical care. Am J Hosp Pharm. 1990;47:533-543.

10. Koecheler JA, Abramowitz PW, Swim SE, Daniels CE. Indicators for the selection of ambulatory patients who warrant pharmacist monitoring. Am J Hosp Pharm. 1989;46:729-732.

11. Isaksen SF, Jonassen J, Malone DC, Billups SJ, Carter BL, Sintek CD. Estimating risk factors for patients with potential drug-related problems using electronic pharmacy data. IMPROVE investigators. Ann Pharmacother. 1999;33:406-412.

12. Barenholtz Levy H. Self-administered medication-risk questionnaire in an elderly population. Ann Pharmacother. 2003;37:982-987. 
13. George J, Munro K, McCaig D, Stewart D. Risk factors for medication misadventure among residents in sheltered housing complexes. $\mathrm{Br} \mathrm{J}$ Clin Pharmacol. 2007;63:171-176.

14. Pit SW, Byles JE, Cockburn J. Prevalence of self-reported risk factors for medication misadventure among older people in general practice. J Eval Clin Pract. 2008;14:203-208.
15. Langford BJ, Jorgenson D, Kwan D, Papoushek C. Implementation of a self-administered questionnaire to identify patients at risk for medication-related problems in a family health center. Pharmacotherapy. 2006;26:260-268.

16. Carter BL, Malone DC, Billups SJ, et al. Interpreting the findings of the IMPROVE study. Am J Health Syst Pharm. 2001;58:1330-1337.

\section{Publish your work in this journal}

The Journal of Multidisciplinary Healthcare is an international, peerreviewed open-access journal that aims to represent and publish research in healthcare areas delivered by practitioners of different disciplines. This includes studies and reviews conducted by multidisciplinary teams as well as research which evaluates the results or conduct of such teams or health- care processes in general. The journal covers a wide range of areas and welcomes submission from practitioners at all levels, from all over the world. The manuscript management system is completely online and includes a very quick and fair peer-review system. Visit http://www.dovepress. com/testimonials.php to read real quotes from published authors.

Submit your manuscript here: http://www.dovepress.com/journal-of-multidisciplinary-healthcare-journal 